\title{
O NOVO CPC E O ACESSO À JUSTIÇA: \\ EM FOCO A TUTELA ANTECIPADA ANTECEDENTE DE SAÚDE
}

\author{
THE NEW CPC AND ACCESS TO JUSTICE: \\ EARLY GUARDIANSHIP OF HEALTH PRECEDENT
}

Silvana Godoi Câmarai

\begin{abstract}
Resumo: A ampliação do acesso à Justiça está nitidamente vinculada à evolução dos direitos fundamentais e do Processo Civil. Nesse contexto, é possível afirmar que a introdução do procedimento de tutelas provisórias antecipadas antecedentes, previsto nos artigos 303 a 304, sexto capítulo da parte geral do Novo Código de Processo Civil, ampliou o acesso à Justiça no tocante à tutela de saúde? Essa é a proposta do presente artigo, que aborda a judicialização da saúde, iniciando com um breve estudo sobre esses direitos, focando a jurisprudência e o contexto processual, tanto na legislação anterior como na abordagem do Novo Código de Processo Civil de 2015, para verificarmos se nesta matéria, houve uma melhora efetiva com a introdução do novo instituto.
\end{abstract}

Palavras-chave: Código de Processo Civil de 2015. Acesso à Justiça. Judicialização da saúde pública no Brasil.

Abstract: The expansion of access to justice is clearly linked to the evolution of fundamental rights and Civil Procedure. In this context, is it possible to state that the introduction of the procedure of provisional preliminary guardianship provided for in articles 303 to 304, sixth chapter of the general part of the New Code of Civil Procedure, increased access to justice in relation to health protection? This is the proposal of this article, which deals with the judicialization of health, starting with a brief study on these rights, focusing on jurisprudence and procedural context, both in the previous legislation and in the New Code of Civil Procedure approach of 2015 , to verify in this area, there was an effective improvement with the introduction of the new institute.

Keywords: Code of Civil Procedure of 2015. Access to Justice. Judicialization of public health in Brazil.

i Servidora Pública da Justiça Federal, Graduada em História pela FFLCH_USP e em Direito pela UNILASSALE-RS. Especialista em Direito Processual Civil e Direito Civil pela Universidade Cândido Mendes-RJ. 


\section{INTRODUÇÃO}

A tutela da saúde representa uma importante demanda da Justiça brasileira, incrementada ainda mais após a Constituição de 1988. A precariedade dos mecanismos administrativos assecuratórios dos direitos fundamentais, previstos nos art. $6^{\circ}$ e 196 da Carta Constitucional, foi o principal motivo para o alargamento dessa demanda. Na realidade, verificou-se que apesar do direito à saúde ter alcançado o status de direito fundamental a ser imposto ao Estado, em todas as esferas da federação, a população permaneceu com restrito acesso a tratamentos médicos e farmacológicos e à Justiça.

Por esse motivo o Poder Judiciário foi instado a examinar inúmeros pedidos de condenação do Estado (União, Estados e Municípios) para fornecimento de medicamentos, tratamentos e terapias. Todavia, tal avaliação continha-se à análise da abusividade negativa, concernente à inércia na implementação de estabelecer um standard mínimo de saúde ao cidadão, evitando um alargamento, por entender que os juízes não podiam adentrar no mérito administrativo, sob pena de prática de ativismo judicial. (SCHULZE, 2014).

Entretanto, as ondas renovatórias do Direito provocaram mudanças na concepção da atuação do Poder Judiciário e no Processo Civil, como veremos adiante.

\section{AS ONDAS DO DIREITO DE ACESSO À JUSTIÇA E OS REFLEXOS NO CPC DE 2015}

O acesso à Justiça é um conceito que se reformula na medida em que a sociedade constrói seus referenciais democráticos. Seu histórico está nitidamente vinculado aos direitos fundamentais e à evolução do Processo Civil.

Cândido Dinamarco (2002, p. 39) explica que o Processo Civil, originariamente, era vinculado ao direito comum e canônico e consagrou sua independência após o século XIX. Durante esse período, manteve-se extremamente formalista e dogmático, pois o processo era considerado ente puramente técnico, desvinculado dos valores da sociedade.

Tal entendimento se alterou com a democratização da sociedade e o processo começou a ser visto como um instrumento, cuja permeabilidade aos valores tutelados na ordem político-constitucional, jurídico-material deveria propiciar o alcance dos fins aos quais se destina. 
Quando alterou-se a visão do processo, como instrumento meramente relacionado à realização dos direitos individuais, o acesso à Justiça deixou de ser tratado como um simples direito de ingresso em juízo, ou seja o mero exercício de direito de ação. Logo, as inibições de acesso à Justiça não podiam mais ser tratadas como fenômenos puramente técnicos do Direito ou ao poder de exercitar a ação, diz Cichocki Neto. (BASSETO, 2016).

Nesse sentido, Kazuo Watanabe (1988, p. 128) formula que o acesso à Justiça não significa apenas o direito de requerer a tutela jurisdicional do Estado. É necessário que ela seja feita de forma ampla, efetiva, igualitária, de modo a proporcionar a todos uma ordem jurídica justa.

Maria de Carmo Lopes Basseto acrescenta: "no contexto atual, o "acesso" não significaria simplesmente um direito social fundamental, mas "o mais básico de todos os direitos [...]" (BASSETO, 2016, p. 26).

No Brasil, onde o processo de democratização ocorreu no final dos anos 80 com a abertura política, o movimento internacional de ampliação do acesso à Justiça teve seus ecos em nosso país tardiamente, porquanto a extensa população marginalizada em virtude da exclusão sócioeconômica-política-jurídica, vez que não tinha acesso a direitos básicos.

Segundo Vladimir Santos Vitovsky $(2015$, p. 14) as reformas relacionadas ao acesso à Justiça ocorridas no novo CPC surgiram em um contexto de crise do Judiciário, retratada especialmente na EC 45/2004, que trouxe alguns princípios norteadores a serem buscados, tais como a duração razoável do processo e meios que garantam a celeridade de sua tramitação. Ademais, salienta o autor, verifica-se que o novo CPC abarca um mosaico de tradições e concepções de acesso à Justiça, abarcando as quatro ondas de acesso à Justiça.

Cappelletti e Garth (1988, p. 49) falam em três ondas do acesso à Justiça. A primeira é a legal aid (1945), a segunda, da representação legal para os interesses difusos (década de 1960), e mais recentemente, o access-to-justice-approach, que inclui os anteriores e vai além, tentando atacar as barreiras ao acesso à Justiça, através das fórmulas alternativas de resolução de conflitos que iniciaram na década de 1970.

Vitovsky (2015, p. 11-12) acrescenta ao debate uma quarta onda de acesso à Justiça, com base no entendimento de Kim Economides. Nela, há a preocupação com a dimensão ética, política da administração da Justiça e de seus operadores. Questionamentos como: o papel do juiz na sociedade no tocante às políticas públicas; a celeridade e a duração razoável 
do processo, a constitucionalização do processo e do acesso à Justiça; a atuação na estrutura do conflito, de acordo com o perfil de litigiosidade; o papel das iniciativas inovadoras (a sociologia das emergências); os vetores da efetividade do processo (simplificação, efetividade, instrumentalismo, minimalismo e maximalismo, organicidade); a participação; a educação para os direitos, com a prestação de informação jurídica.

Entendemos que a quarta onda de acesso à Justiça é que sustentou as modificações no CPC relacionadas à tutela antecedente de saúde, pois foi através dela que se evidenciou a preocupação com a atuação ético-política do juiz nas políticas públicas, a questão da celeridade, da necessidade de constitucionalização do processo e de sua efetividade.

\section{A EVOLUÇÃO JURISPRUDENCIAL DA TUTELA DE SAÚDE}

A judicialização da saúde tornou inevitável o enfrentamento de diversas teses apresentadas pelas partes nos litígios. Vamos apresentar as principais teses, com foco na processualização dessas demandas, contextualizando as questões de mérito para, a seguir, apresentar as mudanças procedimentais ocorridas com o Novo CPC.

Inicialmente, os entes públicos alicerçaram a defesa do Estado na alegação da violação do princípio da separação dos poderes, da reserva do possível e da proibição de antecipação de tutela contra a Fazenda Pública. Mais tarde, vieram as alegações de necessidade de formalização de critérios para deferimento das tutelas concernentes a remédios de alto custo e àqueles não registrados na ANVISA.

Em contraposição, os autores alegavam o direito fundamental à saúde, o princípio da dignidade da pessoa humana e o direito à vida.

Façamos um breve relato de como a jurisprudência dos tribunais superiores trataram estas teses de suma importância para as demandas de saúde.

\subsection{Teses de Violação dos princípios da separação dos Poderes, da "reserva do possível" em contraposição à intangibilidade do mínimo existencial}

Uma das teses mais postuladas pelos entes públicos consistiu em alegar que a determinação do Judiciário para execução de políticas públicas de implementação do direito à saúde, previstos na Constituição, configurava violação do princípio da separação dos poderes. 
No entanto, o STF ao julgar este direito de segunda geração, responsabilidade do Estado, firmou entendimento que não procedia tal tese, quando o Judiciário atuasse na jurisdição constitucional de concretização de direitos fundamentais:

EMENTA: AGRAVO REGIMENTAL EM RECURSO EXTRAORDINÁRIO COM AGRAVO. DIREITO À SAÚDE. FORNECIMENTO PELO PODER PÚBLICO DO TRATAMENTO ADEQUADO. SOLIDARIEDADE DOS ENTES FEDERATIVOS. OFENSA AO PRINCÍPIO DA SEPARAÇÃO DOS PODERES. NÃO OCORRÊNCIA. COLISÃO DE DIREITOS FUNDAMENTAIS. PREVALÊNCIA DO DIREITO À VIDA. PRECEDENTES. A jurisprudência do Supremo Tribunal Federal é firme no sentido de que, apesar do caráter meramente programático atribuído ao art. 196 da Constituição Federal, o Estado não pode se eximir do dever de propiciar os meios necessários ao gozo do direito à saúde dos cidadãos. O Supremo Tribunal Federal assentou o entendimento de que o Poder Judiciário pode, sem que fique configurada violação ao princípio da separação dos Poderes, determinar a implementação de políticas públicas nas questões relativas ao direito constitucional à saúde. O Supremo Tribunal Federal entende que, na colisão entre o direito à vida e à saúde e interesses secundários do Estado, o juízo de ponderação impõe que a solução do conflito seja no sentido da preservação do direito à vida. Ausência de argumentos capazes de infirmar a decisão agravada. Agravo regimental a que se nega provimento

(BRASIL, 2014).

Superado esse debate, ao Judiciário foi permitido atuar como garantidor da função de fornecimento ao cidadão de prestações positivas com ampliação de serviços, desde que voltadas para a satisfação de direitos fundamentais, em especial, aqueles atinentes às necessidades básicas.

Nesse diapasão, o Supremo Tribunal Federal (BRASIL, 2011), firmou jurisprudência que se contrapõe à reserva do possível, a intangibilidade do mínimo existencial. Portanto, não pode haver discricionariedade do ente público quanto à observância de política pública quando tratar de respeito aos princípios da dignidade da pessoa humana, da saúde e do meio ambiente equilibrado. A mera alegação de ausência de previsão orçamentária não tem o condão de afastar a obrigação de garantir o mínimo existencial. Sendo assim, o ente público deve provar a absoluta inexequibilidade do direito social pleiteado por insuficiência de caixa para poder se imiscuir de cumprir com a obrigação. 
No mesmo sentido, os recentes acórdãos do STJ, que dispõem: "em que pese a existência de limitações orçamentárias, esta não pode servir de escudo para recusas de cumprimento de obrigações prioritárias decorrentes de provimento judicial que dê efetividade a direitos fundamentais" (BRASIL, 2017a).

\subsection{Teses de proibição de antecipação da tutela contra a Fazenda Pública, esgotamento do objeto da ação, irreversibilidade da demanda em contraposição ao princípio da dignidade da pessoa humana, especialmente o direito à vida}

No tocante às medidas processuais, restou superada a proibição de antecipação de tutela contra a Fazenda Pública nos procedimentos atinentes à saúde. A Corte Suprema decidiu que nas obrigações de fazer era inaplicável tal proibição, mesmo que a tutela concedida esgotasse o objeto da ação e fosse irreversível. Também admitiu a tutela provisória contra o poder público, quando determinou a entrega de remédio a idoso ou a portador do vírus da AIDS, inclusive bloqueando verbas para garantir a efetividade do julgado (aplicação do art. 536, caput do código anterior):

PROCESSUAL CIVIL. ADMINISTRATIVO. RECURSO ESPECIAL. ADOÇÃO DE MEDIDA NECESSÁRIA À EFETIVAÇÃO DA TUTELA ESPECÍFICA OU À OBTENÇÃO DO RESULTADO PRÁTICO EQUIVALENTE. ART. 461, § 50. DO CPC. BLOQUEIO DE VERBAS PÚBLICAS. POSSIBILIDADE CONFERIDA AO JULGADOR, DE OFÍCIO OU A REQUERIMENTO DA PARTE. RECURSO ESPECIAL PROVIDO. ACÓRDÃO SUBMETIDO AO RITO DO ART. 543-C DO CPC E DA RESOLUÇÃO 08/2008 DO STJ.

1. Tratando-se de fornecimento de medicamentos, cabe ao Juiz adotar medidas eficazes à efetivação de suas decisões, podendo, se necessário, determinar até mesmo, o sequestro de valores do devedor (bloqueio), segundo o seu prudente arbítrio, e sempre com adequada fundamentação. 2. Recurso Especial provido. Acórdão submetido ao regime do art. 543-C do CPC e da Resolução 08/2008 do STJ.

(Brasil. Superior Tribunal de Justiça - REsp: 1069810 RS 2008/0138928-4, Relator: Ministro NAPOLEÃO NUNES MAIA FILHO, Data de Julgamento: 23/10/2013, S1 PRIMEIRA SEÇÃO, Data de Publicação: DJe 06/11/2013) 
Prevaleceu o entendimento que é necessário resguardar o princípio da dignidade da pessoa humana, com base no mínimo existencial, ainda que se esgotasse o objeto da demanda e tornasse irreversível a tutela antecipada, para salvaguardar a realização de medidas médicas urgentes, que assegurem o tratamento necessário à sobrevivência do indivíduo. (STJ, 2 ${ }^{\text {a }}$ T, REsp n. 109473/RS, rel. Min. Helio Mosimann, j. em 23/03/1999, publicado no DPJ de 06/09/1999; STJ $1^{\text {a }}$ T. Resp n. 275649/ SP, rel. Min. Garcia Vieira, j. 07/08/2001, publicado no DPJ de 17/09/2001. Ver: STJ, $1^{a}$,T. Respe n. 746.781/RS, relator para acórdão Ministro Luiz Fux, j. em 18/04/2006, publicado em DJe de 22.05.2006.

\subsection{Tese de impossibilidade de fornecimento de medicamentos fora da lista nacional, experimentais e de alto custo em contraposição ao princípio da dignidade da pessoa humana, especialmente o direito à vida e o caso de dano inverso}

Saliente-se que, no cenário atual, trava-se uma importante batalha jurídica no STF a respeito dos medicamentos de alto custo: o julgamento da ADI 5501 sobre a suspensão da eficácia da lei que autorizou o uso da "pílula do câncer", sobre o fornecimento de medicamentos não registrados na ANVISA (Recurso Extraordinário - RE 657718), bem como daqueles considerados de alto custo (RE 566471).

Até os anos 2000, os Tribunais Superiores vinham entendendo que o direito à vida preponderava sobre todos os direitos sopesados. Todavia, outros parâmetros começaram a ser questionados na prática judiciária no tocante a fornecimento de medicamentos, quando estes estavam fora da lista do SUS, de comercialização fora do território nacional, quando não registrados na ANVISA ou com comprovação científica discutível.

Na STA 175 (BRASIL, 2010) o Supremo Tribunal Federal discutiu se poderia haver o fornecimento de tratamentos não oferecidos no Brasil, bem como daqueles medicamentos em fase experimental, desenvolvidos pelas universidades. A corte decidiu que é importante que o juiz esteja atento se a prestação requerida faz parte de protocolo ou política pública estatal e se há uma omissão administrativa. Se há oferecimento de tratamento alternativo para o problema, podendo o autor contestar, caso seu médico entenda ser a alternativa ineficaz. Os medicamentos e tratamentos experimentais, o Estado não está obrigado a fornecê-los; os tratamentos novos, que não constam nos protocolos do SUS, podem ser deferidos, desde que seguidos de ampla instrução probatória. 
O Supremo Tribunal Federal decidiu recentemente a ADI 5.501 MC, voto do relator Ministro Marco Aurélio, de 19/05/2016, publicado em DJE de 1 de agosto de 2017:

(...) $\mathrm{Na}$ elaboração do ato impugnado, o Congresso Nacional, ao permitir a distribuição de remédio sem o controle prévio de viabilidade sanitária, não cumpriu com o dever constitucional de tutela da saúde da população.

(...) A aprovação do produto no órgão do Ministério da Saúde é condição para industrialização, comercialização e importação com fins comerciais, segundo o art. 12 da Lei 6.360/1976. O registro ou cadastro mostra-se condição para o monitoramento, pela Agência fiscalizadora, da segurança, eficácia e qualidade terapêutica do produto. Ante a ausência do registro, a inadequação é presumida. No caso, a lei suprime, casuisticamente, a exigência do registro da fosfoetanolamina sintética como requisito para comercialização, evidenciando que o legislador deixou em segundo plano o dever constitucional de implementar políticas públicas voltadas à garantia da saúde da população. O fornecimento de medicamentos, embora essencial à concretização do Estado Social de Direito, não pode ser conduzido com o atropelo dos requisitos mínimos de segurança para o consumo da população, sob pena de esvaziar-se, por via transversa, o próprio conteúdo do direito fundamental à saúde. (...) É no mínimo temerária - e potencialmente danosa - a liberação genérica do medicamento sem a realização dos estudos clínicos correspondentes, em razão da ausência, até o momento, de elementos técnicos assertivos da viabilidade da substância para o bem-estar do organismo humano. Salta aos olhos, portanto, a presença dos requisitos para o implemento da medida acauteladora. Ante o quadro, defiro a liminar pleiteada para suspender a eficácia da Lei 13.269/2016, até o julgamento definitivo desta ação direta de inconstitucionalidade" (BRASIL, 2017b).

Veja-se que preponderou o princípio da segurança, sob pena de, sob via transversa, haver um esvaziamento do direito à saúde.

Em geral, as decisões sobre saúde são dramáticas e urgentes, com inadiável necessidade de tutela jurisdicional. Por esse motivo, chegam ao STF pela via da suspensão de liminar impetrada pelo ente público para barrar o cumprimento da decisão nos tribunais a quo. O caso a seguir é emblemático neste sentido. 
Apesar de haver restrição ao fornecimento de medicação não registrada na Anvisa, o Juízo da $2^{a}$ Vara da Fazenda Pública do Acre deferiu a tutela de evidência para fornecimento de medicação de alto custo não constante no protocolo do SUS e sem registro na agência reguladora. A Fazenda Pública do Estado alegou grave lesão à ordem pública pelo custo do medicamento e lesão à saúde pública, por ausência de controle de qualidade do produto. Todavia, a ministra Carmén Lúcia, em notável decisão que privilegia evidentemente o direito à vida, manteve a decisão, que determinou o fornecimento, pelo Estado do Acre, do medicamento Soliris (eculizumab), por ser o único tratamento terapêutico para manutenção da vida de uma criança portadora da Síndrome Hemolítico Urémico Atípica (SHUa), doença rara. A ministra indeferiu o pedido de Suspensão de Liminar (BRASIL, 2017c), sob o fundamento de que "a negativa de tratamento à interessada configura dano inverso, que pode levar a óbito". Asseverou que, ao contrário da fosfoetanolamina sintética, objeto de questionamento na ADI 5.501/DF, medicamento ainda em fase inicial de testes, o fármaco questionado na suspensão de segurança é reconhecido pela comunidade internacional com eficácia comprovada por inúmeros testes e por este motivo não há perigo de dano inverso à saúde pública. In verbis:

"(...) Sem desconsiderar o decidido pelo Supremo Tribunal Federal no julgamento da Medida Cautelar na Ação Direta de Inconstitucionalidade n. 5.501/DF, pela qual determinada a suspensão da Resolução n. 38 da Anvisa e, ainda, que as questões afetas à "obrigatoriedade, ou não, de o Estado, ante o direito à saúde constitucionalmente garantido, fornecer medicamento não registrado na Agência Nacional de Vigilância Sanitária - ANVISA" (RE n. 657.718-RG/MG, Tema n. 500) e à "obrigatoriedade de o Poder Público fornecer medicamento de alto custo" (RE n. 566.471/RN, Tema n. 6), ambos pendentes de julgamento de mérito, poderiam justificar a suspensão da decisão impugnada, verifico que a negativa de tratamento à Interessada configura dano inverso que pode levar a óbito. 14. Como destacado pelo Desembargador Relator do Agravo de Instrumento n. 1000977-15.2016.8.01.0000, "à luz do que foi apresentado até o momento, a postulação cinge-se à única alternativa que a agravada possui para permanecer viva". Cumpre registrar que foi reconhecida essa circunstância fática e considerada nas decisões proferidas pelos Ministros Ricardo Lewandowski (STA n. 761/SP), Ayres Britto (SL n. 558/SP) e Cezar Peluso (SS n. 
4.304/CE e SS n. 4.316/ RO), pelas quais foram negados os pedidos de suspensão de decisões cuja natureza e consequências eram análogas à que se analisa na presente suspensão. Em todas elas foram mantidas as determinações de fornecimento do medicamento Soliris (eculizumad)". V. Ademais, não merece prosperar a alegação de falta de comprovação da eficácia do medicamento requerido, na medida em que o fármaco é capaz de proporcionar melhor qualidade de vida ao paciente, a justificar a procedência do pedido inicial, notadamente porque a saúde, incluindo-se a assistência farmacêutica, é direito de todos e dever do Estado, a ser cumprido em relação a todos que comprovadamente necessitem do serviço de saúde, como na espécie dos autos, fazendo o paciente jus ao fornecimento do necessário fármaco, tal como prescrito pelo médico que o atende e que conhece suas reais necessidades. VI. Nesse contexto, caracterizada, na espécie, a impossibilidade de o autor arcar com os custos do tratamento da enfermidade que o acomete, o fornecimento do medicamento requerido, na dosagem e quantidade indicadas pelo médico responsável pelo seu acompanhamento, é medida que se impõe, possibilitandoIhe o exercício do seu direito à vida, à saúde e à assistência médica, como garantia fundamental assegurada em nossa Carta Magna, a sobrepor-se a qualquer outro interesse de cunho político e/ou material. Precedentes. VII. Apelação do autor provida. Agravo regimental da União Federal prejudicado. (Apelação Cível 0063902-58.2011.4.01.3400/ DF, rel. Des. Federal Souza Prudente, unânime, julgado em 22/03/2017, p. 2.720)

\section{A SISTEMATIZAÇÃO DA JUDICIALIZAÇÃO DA TUTELA DE SAÚDE}

No âmbito processual, a partir de 2009, para fazer frente à crescente demanda, buscou-se uma sistematização da judicialização da saúde, com a atuação direta do CNJ. Houve a criação de grupo de trabalho para estudo e medidas concretas para as demandas judiciais (Portaria 650/2009). Desses debates decorreram a edição da Recomendação CNJ n. 31/2010 e mais tarde da Resolução n. 107/2010, que instituiu o Fórum Nacional do Judiciário para monitoramento das demandas de assistência à Saúde. - Fórum da saúde. 
No entanto, a judicialização da saúde pública seguia o procedimento comum, dificultando o acesso à Justiça, a celeridade e a efetivação do resultado útil do processo. Mesmo com as antecipações de tutela, nas causas de comprovada urgência, o processo continuava caro, demorado e com pouca efetividade, por conta dos entraves processuais.

\section{O NOVO CPC E TUTELA PROVISÓRIA ANTECIPADA, ANTECEDENTE DE SAÚDE}

Para assegurar o resultado prático do processo, as tutelas de urgência no Código de Processo Civil em 1939 eram determinadas com base no artigo 675, no poder geral de cautela, a qual permitia medidas provisórias que acautelassem direitos passíveis de perecimento ou de prejuízos graves de difícil reparação.

No entanto, os entraves burocráticos ainda eram muitos. Em 1994, a lei 8.952 de 13 de dezembro possibilitou a antecipação dos efeitos da tutela final com base nas alterações ao artigo 273 do código de 1939.

Embora tal instituto tenha tido êxito, ainda era necessário uma maior adequação aos princípios constitucionais, mormente às críticas advindas da quarta onda de acesso à Justiça.

Por esse motivo, em 2003, foi montada uma comissão com brilhantes processualistas como Ada Pellegrini Grinover, Luiz Guilherme Marinoni, Kazuo Watanabe e Roberto Bemaque, que tinham percepção da necessidade de melhoras nos procedimentos de acesso à Justiça, bem como de promover a estabilização da tutela antecipada no ordenamento jurídico. Para isso seria necessário criar um procedimento mais célere, simplificado e efetivo para as tutelas de urgências, a qual restou prevista no livro $6^{\circ}$, dentro da parte geral do NCPC.

Bedaque (2005, p. 661) explica que o esboço do projeto previu o cabimento de tutelas antecipadas autônomas antecedentes, capazes de lograr força de coisa julgada, caso restasse preclusa a decisão concessiva da medida no lapso de 60 dias.

Os atuais artigos 303 a 304 do NCPC regulam esta matéria. A tutela provisória antecipada antecedente pode englobar tanto a urgência cautelar, que visa à conservação dos direitos, quanto a satisfativa.

Devido ao caráter informal, simplificado e efetivo do requerimento da tutela antecipada autônoma antecedente, cabe às partes decidir sobre a conveniência da instauração e do prosseguimento da demanda para se obter a cognição plena e exauriente do juiz. 
Sendo estas contemporâneas à propositura da ação, evidenciados a probabilidade do direito, perigo de dano ou risco ao resultado útil do processo, tal procedimento pode ser adotado e o pedido pode ser de imediato apreciado pelo juiz.

Tal pedido pode limitar-se ao requerimento da tutela antecipada e à indicação do pedido de tutela final, com breve exposição da lide e do direito.

Sendo assim, atualmente, no pedido de tutela autônoma antecedente, o juiz aprecia a petição inicial, independente de processo e pode de plano conceder a tutela antecipada, devendo o autor aditar, complementar sua argumentação, juntar documentos e formular a confirmação do pedido de tutela final, em 15 (quinze) dias ou em outro prazo maior que o juiz fixar, nos mesmos autos, sem incidência de novas custas processuais.

A seguir, o réu será citado e intimado para a audiência de conciliação ou de mediação na forma do art. 334. Não havendo contestação ou manifestação nessa audiência, tornar-se-á estável a decisão, nos termos do art. 304 do Novo CPC.

Os efeitos decisórios serão mantidos, enquanto não revista, reformada ou invalidada a decisão, por meio de ação autônoma. Parece-nos que o legislador quis dar a máxima validade à decisão, a ponto de só ser revista, quando questionada em outro processo no mesmo juízo que proferiu a decisão.

\section{CONCLUSÃO}

A morosidade da prestação jurisdicional, sobrecarga de processos, complicações procedimentais, limitava por demasiado o acesso à Justiça, tornando o processo ineficiente ou ineficaz. Tal situação, juntamente com o processo de democratização da sociedade, fomentou uma crise no Processo Civil.

A situação era mais grave nas tutelas de urgência, em especial nas de saúde, onde a demora no atendimento poderia significar a perda do direito ou prejuízo irreparável. O Código de Processo Civil anterior, mesmo com a reforma advinda em 1994, pela lei 8.952 de 13 de dezembro que trouxe as alterações do artigo 273 do código de 1939, manteve entraves burocráticos e o procedimento comum com algumas modificações para as tutelas de urgência. 
Então, em casos concretos, onde a pessoa estivesse em estado grave, precisando de um leito hospitalar ou remédio, em risco de vida e, por ineficiência administrativa do Estado, tivesse quer recorrer ao Poder Judiciário, teria que enfrentar diversos óbices de acesso à Justiça, tais como: contratação de advogado, pagamento de custas, início de procedimento de urgência mediante cautelar ou um processo com pedido de antecipação de tutela. Acreça-se a este demorado trâmite de acesso, que o processo seguiria o procedimento comum, com a necessidade de apresentação de procuração, documentação comprovatórias dos direitos do requerente, para finalmente ser distribuído às Varas e permitir a conclusão ao juiz. Neste ritual se o juízo não estivesse suficientemente convencido da situação, adiaria a apreciação da tutela para depois da oitiva do réu, o que demoraria ainda mais o acesso à tulela requerida.

Desta forma, sopesando os valores da segurança jurídica, da dignidade da pessoa humana, o direito à vida, o princípio da eficiência que deve reger a Administração Pública e o direito ao acesso à Justiça de forma mais plena, verificava-se que ainda era necessário uma maior adequação do Processo Civil aos princípios constitucionais, mormente às críticas advindas da quarta onda de acesso à Justiça.

Foi nesse contexto que foram criadas as tutelas antecipadas autônomas antecedentes, na busca de ampliação do acesso à Justiça de forma mais plena e eficaz. O grande entrave da morosidade impedia a efetivação do direito ou o tornava inócuo. Nos casos de tutela da saúde, nos casos mais graves, o requerente morria junto com o seu direito a postular a tutela judicial, antes de analisada sua demanda.

Com o procedimento previsto pelo artigos 303 a 304 do NCPC, o requerente que estiver em estado grave ou correndo risco de dano irreparável poderá postular ao juízo seu direito, independente de recolhimento de custas, procuração e da existência de um processo. O juiz apreciará a petição e, de plano, poderá conceder a tutela antecipada, permitindo $a$ posteriori, ao autor, aditar a petição inicial, bem como complementar sua argumentação, juntar documentos e a confirmação do pedido de tutela final, em 15 (quinze) dias ou em outro prazo maior que o juiz fixar.

Percebe-se que a adoção deste procedimento mais simplificado e rápido propiciou melhora no acesso à Justiça. Hoje não há mais a necessidade de se requerer uma tutela cautelar em caráter antecedente em um processo preparatório como existia no CPC de 1973. 
Logo, verifica-se que houve um ganho em celeridade e ampliou-se o acesso à Justiça, principalmente nos casos em que a demora pode significar a perda efetiva de um direito ou a impossibilidade de sua apreciação pelo Judiciário.

Conclui-se que, considerando que o direito à vida e à saúde é o mais premente dos direitos, o procedimento previsto no capítulo sexto, parte geral do Novo Código de Processo Civil, ao privilegiar a simplicidade, informalidade, celeridade e efetividade, consistiu em uma forma de ampliação ao acesso à Justiça aos cidadãos.

\section{REFERÊNCIAS}

BASSETO, Maria do Carmo Lopes Toffanetto Rossitto. Democratização do acesso à Justiça: análise dos Juizados Especiais Federais itinerantes na Amazônia Legal brasileira. Brasília: Conselho da Justiça Federal, Centro de Estudos Judiciários, 2016.

BEDAQUE, José Roberto dos Santos. Estabilização das tutelas de urgência. In: Estudos em homenagem à professora Ada Pellegrini Grinover. YARSHELL, Flávio Luiz; MORAES, Mauricio Zanoide de; ACHILLE, Saletti (Org.). São Paulo: DPJ Editora, 2005.

BRASIL. Supremo Tribunal Federal. Ação direta de inconstitucionalidade ADI 5.501 MC, voto do rel. min. Marco Aurélio, j. 19-5-2016, P. Diário da Justiça Eletrônico, 1 ago. 2017b A constituição e o Supremo [recurso eletrônico]/Supremo Tribunal Federal, Brasília: Secretaria de documentação, 2017b, modo de acesso: <http:www.stf.jus.br/portal> item 203 de 378, vide : art. 196 da Constituição anotada.

BRASIL. Supremo Tribunal Federal. Agravo regimental em recurso extraordinário com agravo ARE 801676. Relator: Ministro Luís Roberto Barroso, Primeira Turma. Brasília, 19 de agosto de 2014. Diário da Justiça Eletrônico, n. 170, 03 set. 2014.

BRASIL. Superior Tribunal de Justiça. Agravo regimental no agravo em recurso especial $n^{\circ}$ 649.229/MG, Relator: Ministro Napoleão Nunes Maia Filho, Primeira Turma. Minas Gerais, 28 de março de 2017, Diário da Justiça Eletrônico, 06 de março de 2017a. No mesmo sentido: 
Agravo regimental no agravo em recurso especial $n^{\circ} 1234968$ SC 2011/0018728-7, Relatora: Ministra Regina Helena Costa, Diário da Justiça Eletrônico, 09 de agosto de 2017a.

BRASIL. Supremo Tribunal Federal. Agravo regimental no recurso extraordinário com agravo $n^{\circ}$ 639.337/SP. Relator: Ministro Celso de Mello. São Paulo, 23 agosto de 2011. Diário da Justiça Eletrônico, n. 177, 15 set. 2011, Ementário n²587-01.

BRASIL. Supremo Tribunal Federal. STA 175-AgR/CE. Relator: Ministro Gilmar Mendes. Agravante: União Federal. Agravados: Ministério Público; Clarice Abreu, Estado do Pará e Município de Fortaleza. Diário da Justiça Eletrônico, n. 76, 30 mar. 2010. Ementário n. 2399-1.

BRASIL. Supremo Tribunal Federal. Suspensão de Liminar 1.053 - AC. Agravo de Instrumento n.1000977-15.2016.8.01.0000. Requerente: Estado do Acre; Requerido: Tribunal de Justiça do Estado do Acre. Apelação Cível 0063902-58.2011.4.01.3400/DF, Relator: Desembargador Federal Souza Prudente, unânime. 22 de março de 2017. Revista do Tribunal Regional da $1^{\text {a }}$ Região, v.29, n.3/4 p. 122-123, março/abril 2017c.

BRASIL. Senado. Lei 13105, de 17 de março de 2015. Código do Processo Civil. 255 p., Disponível em: <http://www2.senado.gov.br/bdsf/ handle/id/507525>. Acesso em: 30 maio 2018.

CAPPELLETTI, Mauro; GARTH, Bryant. Acesso à Justiça. Trad. Ellen Gracie Northfleet. Porto Alegre: Fabris, 1988.

DINAMARCO, Cândido Rangel. A Instrumentalidade do Processo. 10. ed. São Paulo: Malheiros, 2002.

GRINOVER, Ada Pellegrini. Novas tendências do Direito Processual: de acordo com a Constituição de 1988. Rio de Janeiro: Forense Universitária, 1990.

SCHULZE, Clenio Jair. A judicialização da saúde e o Conselho Nacional de Justiça. Revista de Doutrina da $4^{\text {a }}$ Região, Porto Alegre, n. 58, fev. 2014. Disponível em: <http://www.revistadoutrina.trf4.jus.br/ artigos/edicao058/Clenio_Schulze.html>Acesso em: 05 jul. 2017. 
VITOVSKY, Vladimir Santos. O acesso à justiça no Novo Código de Processo Civil: continuidades, inovações e ausências. Revista CEJ, Brasília, DF, v. 19, n. 67, p. 7-17, set./dez. 2015.

WATANABE, Kazuo. Acesso à Justiça e Sociedade Moderna. In: GRINOVER, Ada Pellegrini; DINAMARCO, Cândido; WATANABE, Kazuo (Org.). Participação e Processo. São Paulo: Revista dos Tribunais, 1988. p. 128-135. 